Short Communication

\title{
Investigation of Chloride Transference in Reinforced Concrete Structure using Electrochemical Chloride Extraction Process
}

\author{
Xingwang Liu, Ning Xue, Hanbo Jia, Yingshuai Wu and Jingjun Ma* \\ College of Science and Technology, Agricultural University of Hebei, Huanghua, 061100, P.R. China \\ *E-mail: mjjwjpmartin@sina.com
}

doi: $10.20964 / 2016.08 .30$

Received: 17 March 2016 / Accepted: 31 May 2016 / Published: 7 July 2016

\begin{abstract}
Electrochemical chloride extraction (ECE) is an effective method for rehabilitating reinforced concrete structure damaged by the corrosion process. The understanding of the chloride transference in reinforced concrete structure during ECE process is essential for further exploring the ECE mechanism and propose the mathematical model. In this paper, we used an embeddable chloride probe and chemical titration analysis for analyzing the chloride content in different depth of the concrete structure during the ECE process. Moreover, the decomposition of bound chlorides during the ECE process was also investigated.
\end{abstract}

Keywords: Electrochemical chloride extraction; Reinforced concrete; Chloride transference; Current density

\section{FULLTEXT}

(C) 2016 The Authors. Published by ESG (www.electrochemsci.org). This article is an open access article distributed under the terms and conditions of the Creative Commons Attribution license (http://creativecommons.org/licenses/by/4.0/). 